

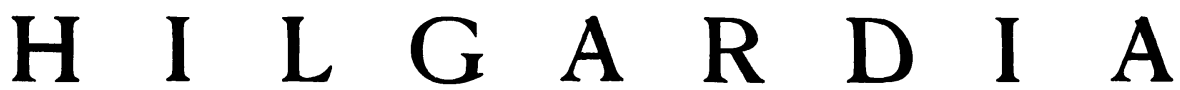

A Journal of Agricultural Science Published by

the California Agricultural Experiment Station

VoL. 17

DECEMBER, 1947

No. 19

\section{EFFECTS OF POTASH DEFICIENCY AND EXCESS ON ORANGE TREES ${ }^{1,2}$}

\author{
H. D. CHAPMAN, ${ }^{3}$ S. M. BROWN, ${ }^{4}$ AND D. S. RAYNER ${ }^{5}$
}

\section{INTRODUCTION}

MANY FIELD TRIALS to determine whether citrus would respond to potash have been made in California. No clear-cut indications of the need of potash have come from the tests (Parker and Batchelor, 1942). ${ }^{6}$ Despite these results, many experienced growers are convinced that potash is indispensable to the maintenance of good quality or production or both, and persist in its use. In an effort to throw further light on the problem, a systematic study was begun by the authors some years ago. Work consisted first in determining the amounts of total, exchangeable, and water-soluble potassium in commercial orchards as compared with the amounts in adjacent nonfertilized areas. ${ }^{7}$ This survey revealed wide differences in the potash content of citrus orchard soils, suggesting that in some groves potash might be deficient and that in others it might have accumulated to the point of excess.

Subsequent efforts were therefore directed toward three objectives : (1) to determine the characteristic effects of potash deficiency and excess on bearing citrus trees; (2) to determine the extent to which fruit quality is influenced by potash variations; and (3) to determine whether the potash content of the leaf or of any other part of the citrus tree is a reliable index of potash deficiency or excess.

An exploratory greenhouse experiment with citrus seedlings and cuttings to determine the effects of potash deficiency under a variety of nutrient conditions was carried out (Chapman and Brown, 1942b). This was followed by an outdoor experiment with bearing trees, and it is with this latter experiment that the present paper is concerned.

\footnotetext{
${ }^{1}$ Received for publication October 29, 1946.

${ }^{2}$ Paper No. 563, University of California Citrus Experiment Station, Riverside, California.

${ }^{3}$ Professor of Soils and Plant Nutrition and Chemist in the Experiment Station.

${ }^{4}$ Associate Chemist in the Experiment Station.

"Senior Laboratory Technician in the Experiment Station.

"See "Literature Cited" for citations, referred to in the text by author and date.

${ }^{7}$ Unpublished data on file in the Division of Soils and Plant Nutrition, University of California Citrus Experiment Station.
} 


\section{REVIEW OF LITERATURE}

To the authors' knowledge no one has grown bearing citrus trees in controlled nutrient media of variable potassium supply over a long enough period to determine the effects of both potash deficiency and excess on the growth, foliage, composition, and fruit quality. Reed and Haas (1923) grew young orange trees in sand culture without potassium (sodium was substituted for potassium) for 17 months. Only the very earliest stages of potassium deficiency developed during this period. In describing these early symptoms, the authors state that some of the leaves produced were undersized and that the chlorophyll in some was faded. These effects were more pronounced on the south side of the tree. Some iron chlorosis was also seen. Haas (1936) later grew young citrus trees in sand cultures lacking potassium. He noted some scorching of leaves, twig dieback, and gum exudation on the wood. Some of the leaves showed resinous spots. No fruit was produced on these trees. Bryan (1935) grew grapefruit seedlings in potassium-deficient cultures and noted first a stimulation of growth, followed later by retardation. There was leaf puckering, and the fading of chlorophyll in small irregular spots on the leaf. Bryan also noted pustularlike brown spots on the leaves. The branches drooped and showed a lack of rigidity. Eckstein, Bruno, and Turrentine (1937), in their compilation of data on potash deficiency, cite leaf puckering along the midrib, and brown necrotic spots on leaves as indications of potassium lack in citrus. They also indicate that fruit from trees minus this element has thick, rough rind, and that its keeping quality is impaired.

In a Florida field experiment with oranges on Norfolk sand, Bahrt and Roy (1940) report that lack of potassium reduced yields and diminished fruit sizes. The potassium-deficient fruit had thinner rinds, contained less acid, but was slightly higher in soluble solids than fruit from trees receiving potash. Roy (1945), studying the juice characteristics of fruit from these plots, found less vitamin $\mathrm{C}$ in the potassium-deficient fruit although the difference was very slight (0.48 compared with $0.54-0.55 \mathrm{mgm}$ per $\mathrm{ml}$ ). He also found less citric acid, more reducing and total sugars, and less potassium in the juice of potassium-deficient oranges.

Young (1917), in California, found that nitrogen slightly decreased sugars, and very slightly increased acidity, but that phosphorus and potassium.were without effect. Webber, writing in 1895 on early-day beliefs of growers in Florida, stated that potassium increased the acidity of fruit and lowered the sugar content. In the analysis of Florida fruit sent in from groves receiving low- and high-potassium fertilization, Collison (1913) found acidity to be slightly increased in the fruit from potash-treated trees. Camp, Gaddum, and Stahl (1933), in studies of Florida grapefruit under cold storage, concluded that potassium increased acidity and decreased sugar. Van der Plank and Turner (1936) found in fertilizer experiments with oranges in the western Transvaal, South Africa, that while without effect on yield, potassium sulfate increased fruit acidity. Anderssen (1937), reporting on a citrus fertilizer experiment in South Africa, found that, while potash was without effect on yield, juice acidity was increased, as was rind thickness. Allwright (1938), reporting on fertilizer experiments in the western Transvaal, South Africa, 
states that potassium sulfate increased fruit acidity. Neetles and Forsee (1941), reporting on an orange fertilizer experiment on a peat soil in Florida, found that fruit sizes were increased by potash.

Morris (1937), reporting on field fertilizer experiments with oranges in southern Rhodesia, South Africa, noted that increased fruit acidity resulted from potash additions. There was no significant effect on soluble solids.

Provan (1938), in connection with field fertilizer trials with navel oranges in Australia, found no evidence of an effect of potash on fruit quality.

Benton and Stokes (1931) report that in field experiments with oranges in Australia, a lack of potash resulted in smaller-sized fruit. These fruits were smoother, on the average, than fruit from potash-treated trees. The juice from fruit of potash-treated trees was lower in sugars and higher in nonsugars. Parker and Batchelor (1942), reporting on a number of fertilizer experiments in California, state that no significant effects on yield or on the commercial quality of fruit were obtained from applications of potash.

Relative to potassium excess, the authors know of no data with bearing citrus trees, but foliage symptoms on seedlings and cuttings grown in nutrient media have been described by several investigators (Chapman, Liebig, and Vanselow, 1939; Haas, 1932 ; Oppenheimer and Mendel, 1938).

\section{EXPERIMENTAL METHODS}

Materials and Technique. For this experiment a group of four-year-old orange trees (Valencias and Washington Navels on sour rootstock) were grown in water culture in large concrete containers of 700-liter capacity. The trees were originally procured from a commercial nursery as one-year-old budded trees, and were grown from June, 1936, to June, 1940, in 25-gallon sand cultures. By 1940 they had outgrown the sand cultures and were transferred to the concrete containers. These containers were cylindrical cement conduits provided with cement bottoms, and were painted inside and out with an asphaltum product. They were three quarters buried in the ground. Painted cement lids in two semicircular sections, with a semicircular hole at the center of each to accommodate the tree trunk, were used as covers.

Twenty trees in all were used to start with, but, during the six-year-period of this experiment (June, 1940, to June, 1946), five of the trees were discarded for one reason or another. At the outset, the trees were divided into three groups : one group received potassium sufficient to maintain concentrations between 3 and 7 p.p.m.; another, 30 to 40 p.p.m.; and the third, 300 to 400 p.p.m. (referred to in table 1 as 7, 39, and 390 p.p.m., respectively). During the first two years, these concentrations had to be adjusted somewhat, but from 1942 to 1946 all were held at constant potassium levels. In order to present for each tree the potassium-nutrition and tree-condition changes which obtained during the period of this experiment, a chronology for each of the trees is given in table 1 . The 390 p.p.m. potassium concentration proved excessive, and the trees given this treatment were subsequently adjusted downward to 117 p.p.m. Trees originally in the 39 p.p.m. group were adjusted upward to 117 p.p.m. in April, 1942. Some of the trees of the 3 to 7 p.p.m. group were reduced to 1.5 p.p.m. and when, after a year, no sign of potassium deficiency developed, were further reduced to 1 p.p.m. As will be seen in table 1, begin- 


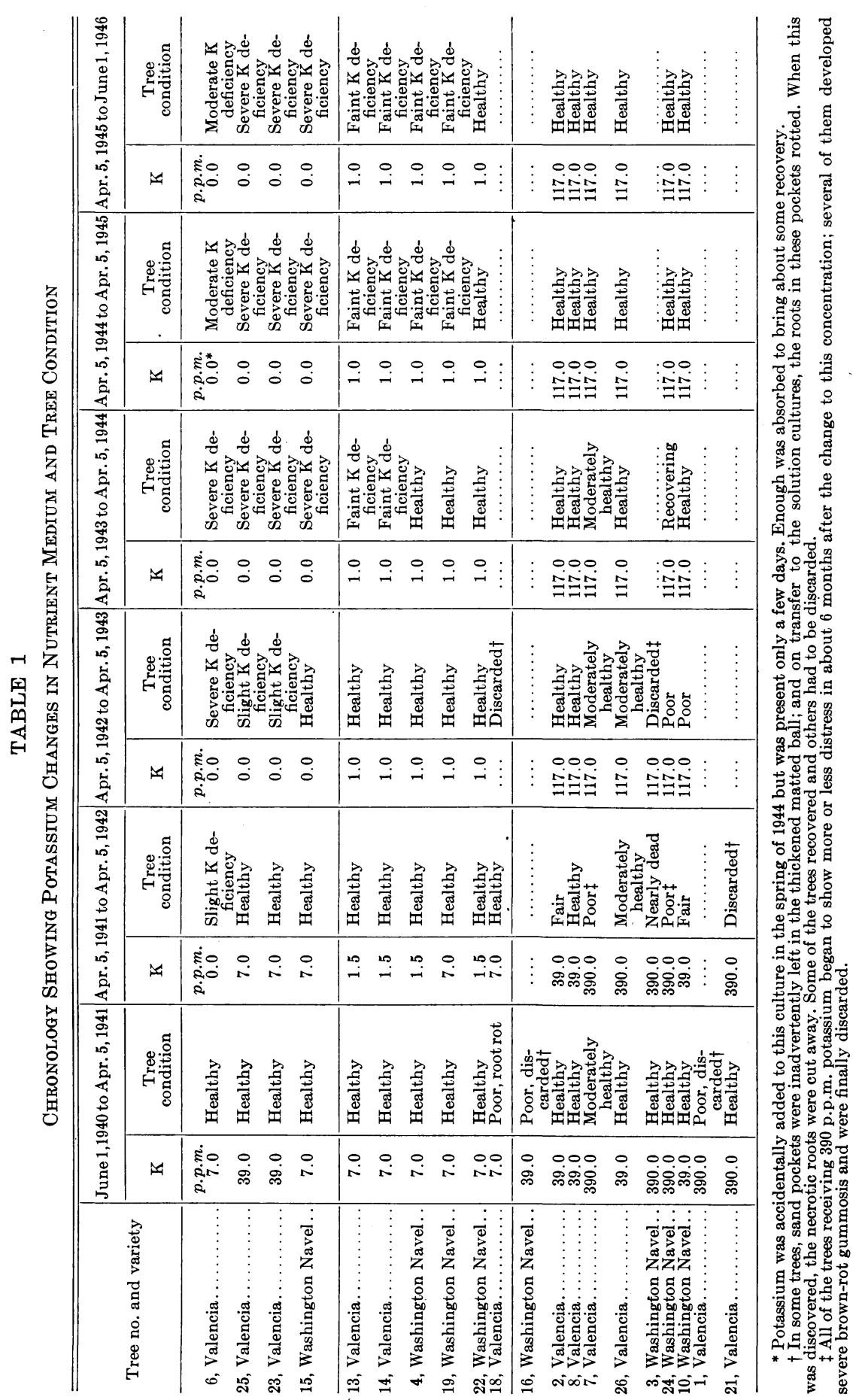




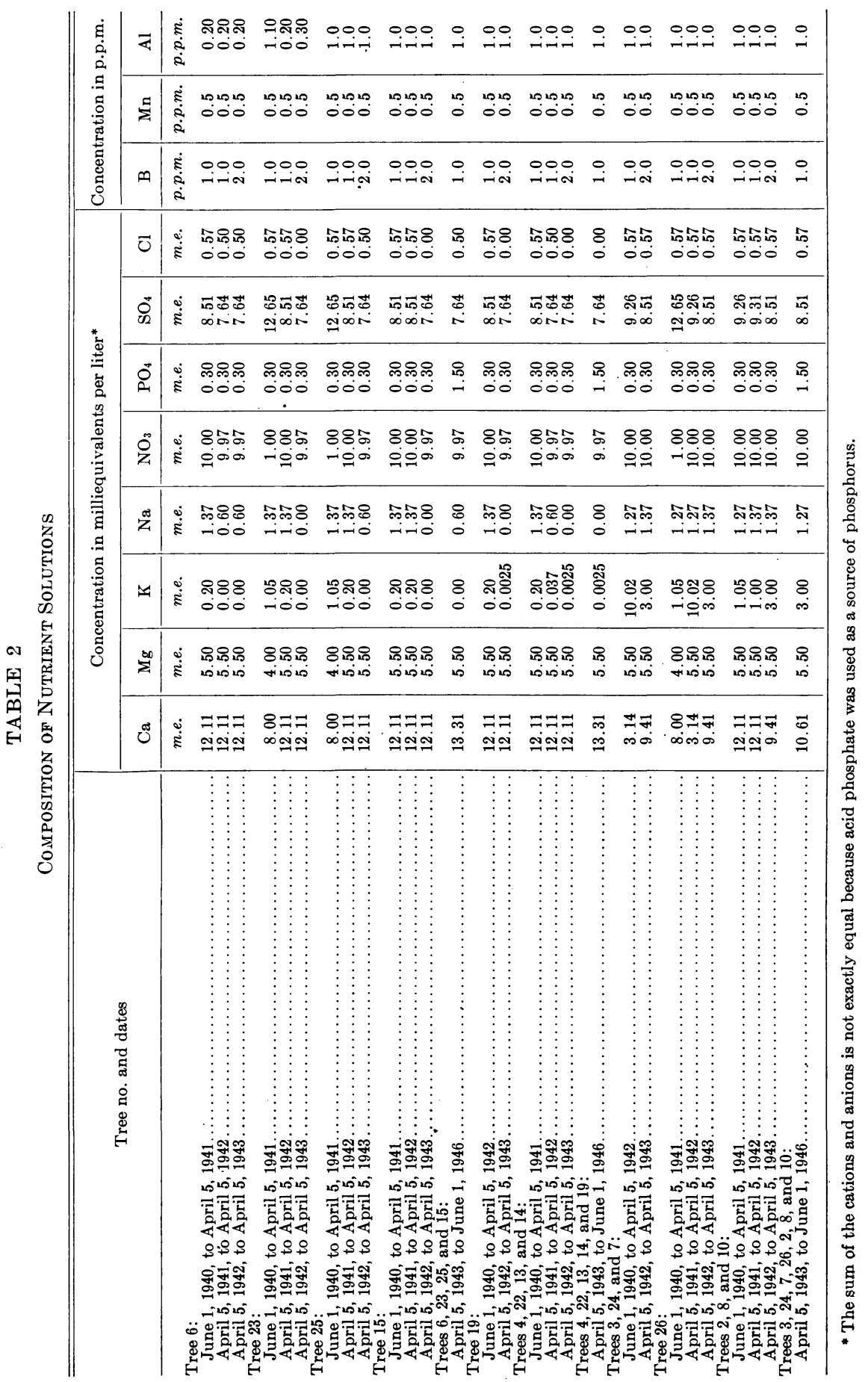


ning in April, 1942, four trees had been deprived of potassium completely; five trees were reduced to 1.0 p.p.m.; and seven trees were receiving 117 p.p.m. potassium. The potassium concentrations of the nutrient solutions as stated, were not changed from this time on.

The composition of the complete nutrient solutions supplied each tree from June, 1940, to June, 1946, are shown in table 2. In addition to the ions shown in table 2 , iron was added three times a week at a rate each time to provide 0.1 p.p.m. Fe. The solutions were continuously aerated.

Water transpired by the tree was compensated for by additions of distilled water. The solutions were completely renewed at monthly intervals. This technique made it possible to maintain reasonably constant the concentration of all of the major ions. At no time did the trees show signs of zinc, copper, boron, or manganese deficiencies, but in winter some of the trees occasionally displayed slight iron chlorosis. This condition largely cleared itself as the solutions warmed up in the spring.

With nutrient solutions renewed once a month, the cultures were not maintained constantly at the levels designated. Analysis indicated that all of the potassium of the 1 p.p.m. cultures was absorbed in from one to two days. The technique followed with these cultures, therefore, was to add enough potassium to give 1 p.p.m. every week. With this technique, all but one of the trees in this group developed faint, but unmistakable, potassium-starvation symptoms. The 117 p.p.m. cultures actually varied between 90 and 117 p.p.m. potassium.

For the first three years of the experiment, the $\mathrm{pH}$ of the solutions was maintained at approximately $\mathrm{pH} 5.0$, using $\mathrm{NaOH}$ or $\mathrm{H}_{2} \mathrm{SO}_{4}$ to adjust as needed. However, the cultures became infected with Phytophthora parasitica fungus, and the roots of some of the trees turned dark brown and made little new growth. In an effort to provide conditions less favorable for this organism, the $\mathrm{pH}$ of all the cultures was lowered in April, 1943, to $\mathrm{pH} 4.0$. This change brought about a remarkable development of healthy roots, and from then on until the end of the experiment root appearance and growth were excellent.

In all of the cultures, determinations were run as often as required for phosphate, potassium, and nitrate; and appropriate adjustments were made.

Records of Tree Performance. Systematic notes of both root and top behavior were made at periodic intervals throughout the course of the experiment. Photographs, both black-and-white and colored, were taken from time to time of all the trees and of such abnormalities as occurred.

The fruit picked from each tree annually was weighed, counted, and graded for rind texture, stem, and stylar-end characteristics. A measure of average size was obtained by cutting each fruit transversely at its point of maximum diameter and measuring diameter in millimeters. At the same time, measurements were made of rind thickness. In most years a representative sample of fruit was ground in a Waring Blendor and analyzed for inorganic constituents. The remainder of the fruit was juiced, the juice was strained through a 2-mm sieve, and from the weight of the whole fruit and the juice, the percentage of juice was determined. Samples of juice were tested for total solids with a Brix hydrometer, and determinations of acid and vitamin $\mathrm{C}$ were made. The juice was also tasted for palatability and flavor. From the measurements of diameter, an average diameter for all of the fruit from a given tree 
was obtained; and this figure was converted into number of fruits per packed box as an index of size. No statistical studies were made; statements on significance are the authors' interpretation of the data.

\section{RESULTS}

\section{EFFECT OF POTASSIUM DEFICIENCY}

The experiment started with a group of vigorous and healthy four-year-old trees. One group was taken through successive stages from a low, but adequate, potash supply to extreme deficiency. Another group was taken from the same base to just the earliest stages of potash deficiency. A third group was taken from the same base to potash excess. Hence it has been possible to note in detail all of the growth, foliage, and fruit characteristics associated therewith. Since the potash nutrition of each group was constant for the last four years of the experiment it was possible to check on any seasonal or yearly changes in symptomatology. In going from potassium adequacy to deficiency, no material change in osmotic pressure of the solution was required; for the trees were maintained from the outset at a relatively low potash level.

Inorganic Composition of Leaves and Fruit. In the spring of 1941, and each year thereafter, a representative set of the newly emerged leaves from each tree was picked for analysis. Leaves of this same growth cycle were collected each succeeding month until April of the following year. Then in May of the new year the same procedure was repeated. With this record for each tree in the experiment, it has been possible to follow the progressive change in inorganic composition with the adjustment in potassium level and also the change, in any one year, of leaf composition with age. It is not necessary to present the entire leaf-analysis record here, but table 3 shows the year-to-year changes in leaf composition, and table 4 the monthly changes during 1944-45, for six trees. The trees had come into complete adjustment with the solution by 1944 -hence, the monthly changes reflect the effect of age of leaf on composition. Reference to table 3 shows that by August, 1943, trees 25 and 15, lacking potash, had become relatively constant in inorganic composition. The potassium content of 4-month-old spring-cycle leaves from acutely potashdeficient trees fluctuated around 0.2 per cent (see also table 4). Trees 4 and 13 , receiving 1 p.p.m. potassium, however, did not attain equilibrium until 1944. The potash content of leaves from these trees leveled off at around 0.3 per cent. Trees 2 and 24, receiving 117 p.p.m. potash, also failed to reach constant levels until 1944. The potash in leaves from these trees showed values of over 1.0 per cent. On the whole, a fairly good correlation between potassium content of the nutrient medium and leaf content has been found. The general relation between nutrient-solution level of potassium and that found in spring-cycle leaves from 4 to 7 months of age is as follows :

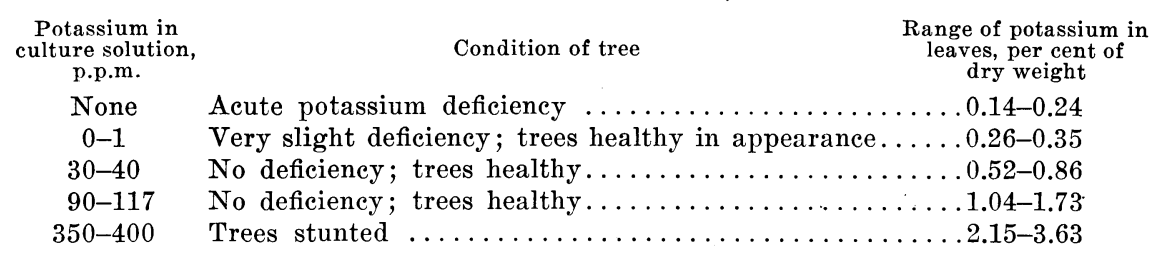


The difference in percentage potash between leaves from trees acutely deficient in potash and trees showing barely perceptible svmptoms is very narrow. But a difference of about 0.1 per cent of potassium in the leaf in this range makes a tremendous difference in tree appearance (compare plates 1 and 3 ).

TABLE 3

Inorganic Composition of Spring-Cycle Leaves in Relation to Potassium Content of Nutrient Medium

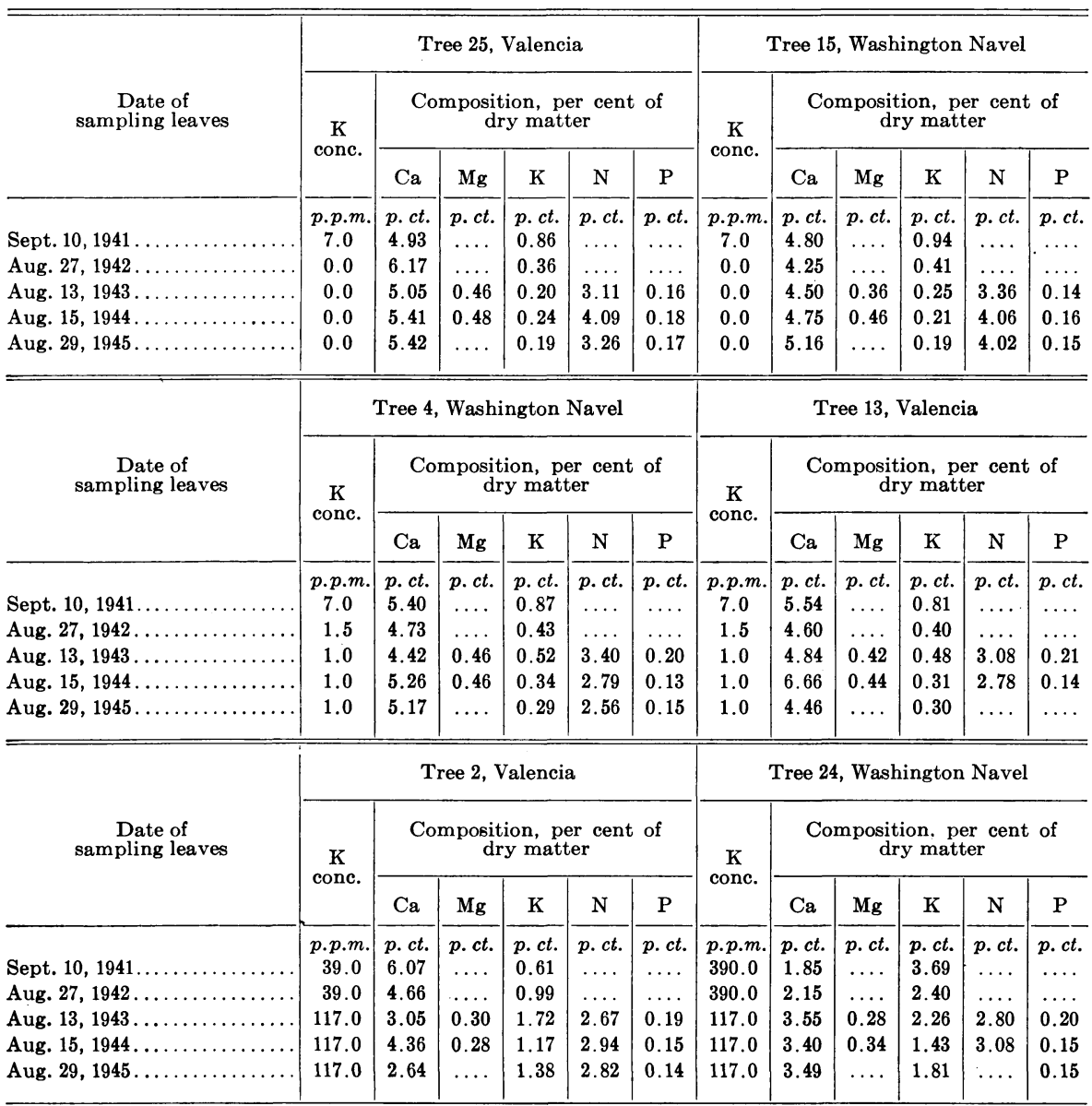

On the other hand, leaves accumulate large quantities of potash if it is present in excess in the nutrient medium-in other words, there is a point at which luxury consumption begins. The range of leaf potassium between extreme deficiency and extreme excess is between 20 and 30 fold.

With respect to the effects of varying potash on the amounts of other constituents, trees 25 to 15 , severely affected by potassium deficiency, are much higher in calcium, magnesium, and nitrogen than are trees 2 and 24, which were given ample potassium. There is a slight indication of higher phosphorus, 
TABLE 4

Change in Composition of Spring-Cycle Leaves with Age in Relation to Potassium LeVel of the Nutrient Medium

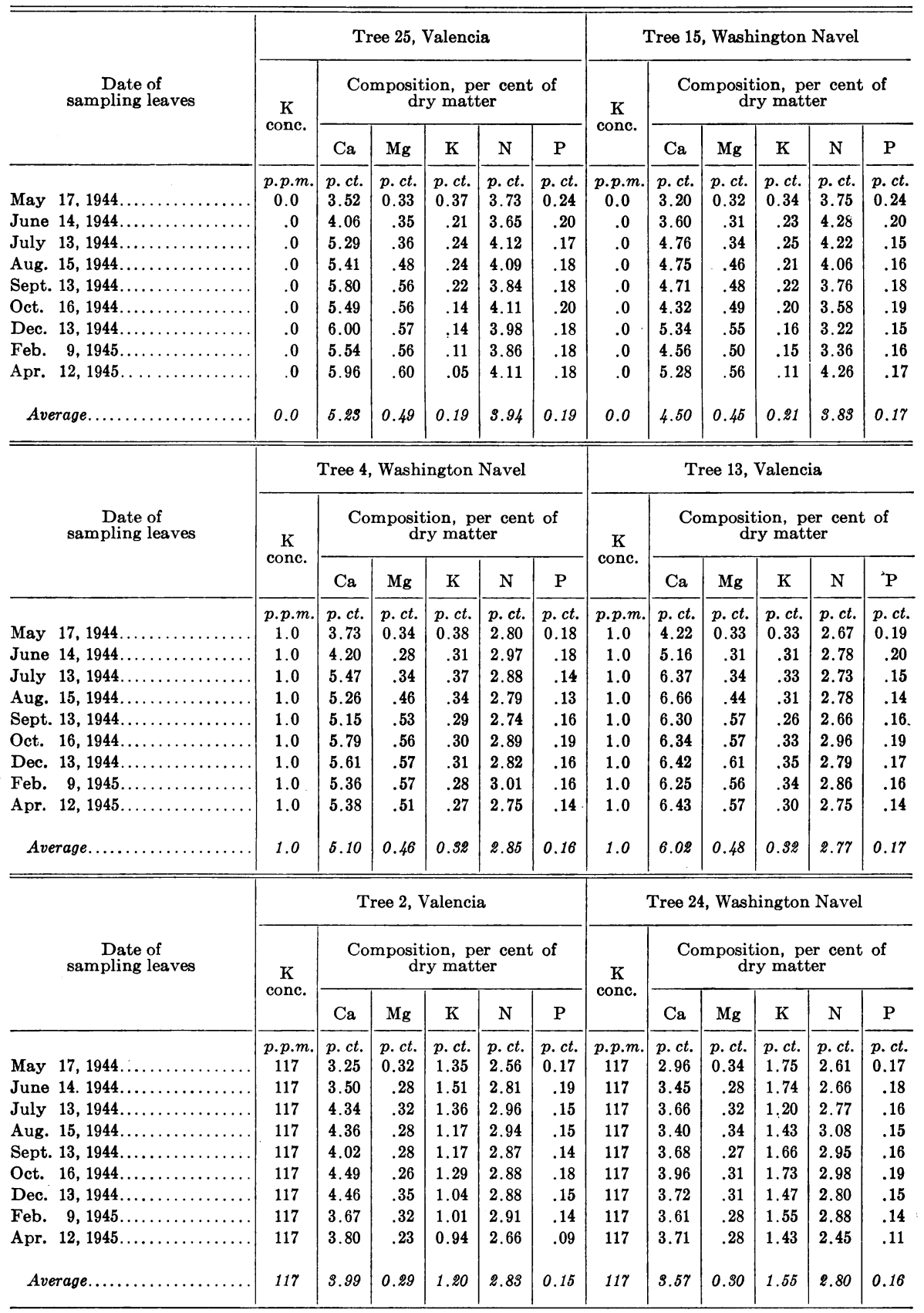


also, but this is of questionable significance. These results are consistent with analyses made of leaves from potash-deficient lemon and orange plants reported in an earlier paper (Chapman and Brown, 1942b).

Trees (nos. 4 and 13) only slightly deficient in potassium were significantly higher in calcium and magnesium than trees (nos. 2 and 24) receiving ample potassium; but the two groups showed no difference in total nitrogen.

The changes, with age, in inorganic composition of leaves are shown in the data of table 4. Very young leaves are characterized by a somewhat lower calcium and magnesium content than older leaves. During the period of July

TABLE 5

Inorganic Composition of Fresh Oranges in Relation to Potassium Supply

\begin{tabular}{|c|c|c|c|c|c|c|}
\hline \multirow{2}{*}{$\begin{array}{l}\text { Potassium in nutrient solution, } \\
\text { tree no., and variety }\end{array}$} & \multirow{2}{*}{$\begin{array}{l}\text { Condition } \\
\text { of tree }\end{array}$} & \multicolumn{5}{|c|}{ Composition, per cent fresh weight } \\
\hline & & $\mathrm{Ca}$ & $\mathrm{Mg}$ & $\mathrm{K}$ & $\mathrm{N}$ & $\mathrm{P}$ \\
\hline 0 p.p.m. K: & & per cent & per cent & per cent & per cent & per cent \\
\hline Tree 15 , Washington Navel. & Slight $\mathrm{K}$ deficiency... & 0.065 & 0.014 & 0.081 & 0.23 & 0.022 \\
\hline Tree 25, Valencia.. & Slight $\mathrm{K}$ deficiency... & .061 & .012 & .064 & .21 & .021 \\
\hline Tree 23, Valencia. . & Slight $\mathrm{K}$ deficiency... & .068 & .012 & .051 & .21 & .030 \\
\hline \multicolumn{7}{|l|}{1 p.p.m. K: } \\
\hline Tree 4, Washington Navel. & Healthy. & .065 & .015 & .095 & .22 & .020 \\
\hline Tree 22, Washington Navel. & Healthy...... & .058 & .015 & .108 & .22 & .025 \\
\hline Tree 19, Washington Navel. . & Healthy............. & .046 & .012 & .111 & .24 & .023 \\
\hline Tree 13, Valencia............ & Healthy ............ & .062 & .015 & .079 & .20 & .023 \\
\hline Tree 14, Valencia. & Healthy..... & .069 & .012 & .096 & .20 & .022 \\
\hline \multicolumn{7}{|l|}{117 p.p.m. K: } \\
\hline Tree 25, Washington Navel. . & Healthy... & .041 & .012 & .185 & .21 & .015 \\
\hline Tree 7 , Valencia............ & Healthy...... & .039 & .012 & .174 & .19 & .022 \\
\hline Tree 2 , Valencia ................ & Healthy............. & .049 & .015 & .163 & .19 & .022 \\
\hline Tree 8, Valencia..... & Healthy.. & 0.048 & 0.014 & 0.166 & 0.21 & 0.016 \\
\hline
\end{tabular}

through October, there is a fair degree of constancy in composition, although, as might be expected, there are some fluctuations. In April, when the blossom and new cycle growth is emerging, there is in most cases a significant decrease in potassium content. On a percentage basis, calcium increases. The trend in magnesium, nitrogen, and phosphorus is not so clear, but in other research there has been noted, in general, a tendency for nitrogen and phosphorus to decrease along with potassium. This tendency suggests that at this stage of development, potassium, nitrogen, and phosphorus are translocated from older leaves to the newly developing parts.

The inorganic composition of mature oranges produced under conditions of variable potassium supply is shown by the data in table 5. Fruit from potassium-deficient trees showed less of this element and more calcium than fruit from trees receiving ample potassium. No significant trend can be seen in the magnesium, nitrogen, or phosphorus content, however.

Tree and Foliage Effects. In April, 1941, tree 6 (Valencia) was deprived of potassium completely. During the ensuing summer and fall, this tree made less vegetative growth. Some of the leaves on the south side became a little bronzed and sunburned; others showed a slight tendency to curl. Lack of new growth caused this tree, by fall, to have less foliage than the rest, although, in general, it had showed health and good color during the first year. 
In April, 1942, at the time of blossoming, there was a greater fall of the old leaves from tree 6 than from the trees receiving potassium. Although a considerable amount of new growth appeared, there was in general less blossom. Many of the old leaves which dropped at this time were quite yellowish (see plate $4, D)$. Lack of growth in the preceding season, and greater leaf fall caused this tree to become much more defoliated than the other trees.

The leaves of tree 6 during the summer and fall of 1942-15 to 18 months after potassium had been omitted from the culture solution-began to show pronounced curling and crinkling. They took on a thick leathery feel and many of them became rather yellowish. Such new growth as emerged from time to time was weak, the leaves were undersized, and some of the stems were at first somewhat yellow at the point of attachment with the larger twigs. This yellowish portion of the stem subsequently greened up but frequently showed an S-like curvature. The tendency for S-shaped laterals was not a pronounced symptom, nor did all emerging shoots show it.

The other trees subsequently deprived of potassium (trees $25,23,15$ ) followed much the same course as tree 6 , the symptoms of potassium lack coming on very slowly. By the spring of 1946 , trees 25,23 , and 15 had reached a state of acute potassium deficiency. Tree 6 , to which potassium had been accidentally added in the summer of 1944 (after which it made some recovery), was in a stage of semiacute deficiency; while trees $13,14,4$, and 19 showed only very slight deficiency. Color pictures depicting these three stages are presented in plates 1,2 , and 3 .

The acute stage (plate 1) is characterized, among other things, by pronounced dieback. The dieback of twigs and branches occurred, in the main, following the spring blossom and growth cycle. The foliage at this stage was yellowish, faded, and lusterless, but there was no definite or distinctive leaf pattern. As stated, severe crinkling, twisting, puckering, and cupping of leaves occurred. These leaves were leathery and thick. Bloom was sparse and new growth was limited. There was always an abnormal leaf fall after the spring flush of growth. With subacute deficiency, the yellowing and curled foliage was less pronounced, there was less dieback, and there was more foliage (plate 2).

Where the deficiency was slight (plate 3 ), there was very little, or nothing, definite or specific by way of foliage color and density, leaf size, or other characteristies by which a positive diagnosis could be made. Having for comparison trees sufficient in potash and, conversely, trees deficient, it was possible to note certain symptoms which indicated slight deficiency. There was a somewhat greater drop of leaves from these trees in the spring of the year than from those receiving sufficient potash. Many of the abscissing leaves were more yellowish than those of normal trees. Here and there could be seen a few crinkled leaves. However, it is always possible to find deformed or somewhat crinkled leaves even on healthy, normal trees; so that this symptom, by itself, is not a clear-cut indication of potassium deficiency. Another indication of potassium lack, which of itself would not be diagnostic for potassium, was a tendency toward less new growth. Another characteristic of these slightly deficient trees was the production of small-sized fruit, which colored earlier than fruit on the trees receiving ample potash. All of these symptoms, together with the low-potash content of the foliage $(0.30$ per cent as against 0.20 for 
the acutely deficient trees and over 1.0 per cent for the amply supplied trees) left no doubt that these trees, although on the whole entirely healthy in appearance, were slightly deficient in potassium.

To illustrate in greater detail the various foliage symptoms characterizing potassium deficiency, a group of color pictures are presented in plate 4. Plate $4, B$, shows potassium-deficient Valencia fruit from tree 6 just turning color, in comparison with fruit $(4, A)$ of the same age from tree 2 receiving ample potash. Note that the potassium-deficient fruit is small but smooth in rind

TABLE 6

Minor-Element Content of Leaves and Fibrous Roots of Orange Trees Deficient and Amply SƯplied with Potash

(Expressed on a p.p.m. in dry-matter basis)

\begin{tabular}{|c|c|c|c|c|}
\hline \multirow{2}{*}{ Element } & \multicolumn{2}{|c|}{ Tree $25, \mathrm{~K}$ deficient } & \multicolumn{2}{|c|}{ Tree 26 , ample $\mathrm{K}$} \\
\hline & Roots & Leaves & Roots & Leaves \\
\hline Silver...... & $\begin{array}{c}\text { p.p.m. } \\
0.4\end{array}$ & $\begin{array}{c}\text { p.p.m. } \\
0.7\end{array}$ & $\begin{array}{c}\text { p.p.m. } \\
0.8\end{array}$ & $\begin{array}{c}\text { p.p.m. } \\
1.0\end{array}$ \\
\hline Aluminum... & 300.0 & 35.0 & 600.0 & 38.0 \\
\hline Boron......... & 40.0 & 210.0 & 95.0 & 160.0 \\
\hline Barium...... & 7.0 & 15.0 & 14.0 & 20.0 \\
\hline Cobalt.............. & 0.5 & N.D. $\dagger$ & N.D. & N.D. \\
\hline Chromium......... & 0.7 & 0.3 & 12.0 & 0.3 \\
\hline Copper..... & $700.0^{*}$ & 28.0 & $1,000.0^{*}$ & 18.0 \\
\hline Iron ........ & $700.0^{*}$ & 35.0 & $1,000.0^{*}$ & 90.0 \\
\hline Manganese... & $700.0^{*}$ & 20.0 & $1,000.0^{*}$ & 40.0 \\
\hline Molybdenum...... & 0.7 & 0.3 & 12.0 & N.D. \\
\hline Nickel........... & 1.3 & 0.7 & 1.0 & 0.8 \\
\hline Lead...... & 85.0 & 8.5 & 60.0 & 6.5 \\
\hline Tin......... & 1.3 & N.D. & N.D. & 2.0 \\
\hline Strontium......... & 20.0 & 30.0 & 240.0 & $1,000.0^{*}$ \\
\hline Titanium............ & 1.3 & 3.0 & 2.0 & 5.0 \\
\hline Vanadium........... & 1.3 & N.D. & 6.0 & N.D. \\
\hline Zinc. & 300.0 & 50.0 & 240.0 & 30.0 \\
\hline Cadmium $\ldots \ldots \ldots \ldots \ldots \ldots \ldots \ldots \ldots \ldots \ldots \ldots \ldots \ldots$ & 6.0 & N.D. & N.D. & N.D. \\
\hline
\end{tabular}

* Figures are approximate.

$\dagger$ N.D. means not detected.

texture. Some of the leaves on this shoot are puckered and somewhat faded but with no definite pattern. Plate 4, $C$, shows mature, potassium-deficient Valencia fruit together with further leaf characteristics. Plate $4, D$, shows the yellow coloration and excessive shedding tendency of old leaves on a potassium-deficient tree after the spring bloom. Plate $4, E, F$, shows the twisting, curling, and puckering of leaves on potassium-deficient trees, together with the yellowing and lack of definite leaf pattern.

It was noted that the roots of the trees, both slightly and acutely deficient in potassium, while of good color, were less branched, the laterals were shorter and more thickened than those of trees receiving ample potash (see plate 5). In earlier greenhouse experiments it was found that potash-deficient plants have a tendency to accumulate boron in their leaves. In an effort to determine whether the root stubbiness noted might be due to toxic accumulations of boron or other elements, spectrographic analyses were made of the fine roots and the leaves from trees 25 and 26 . The results are shown in table 6 . Contrary to expectation, there was in general a lower concentration of minor elements 


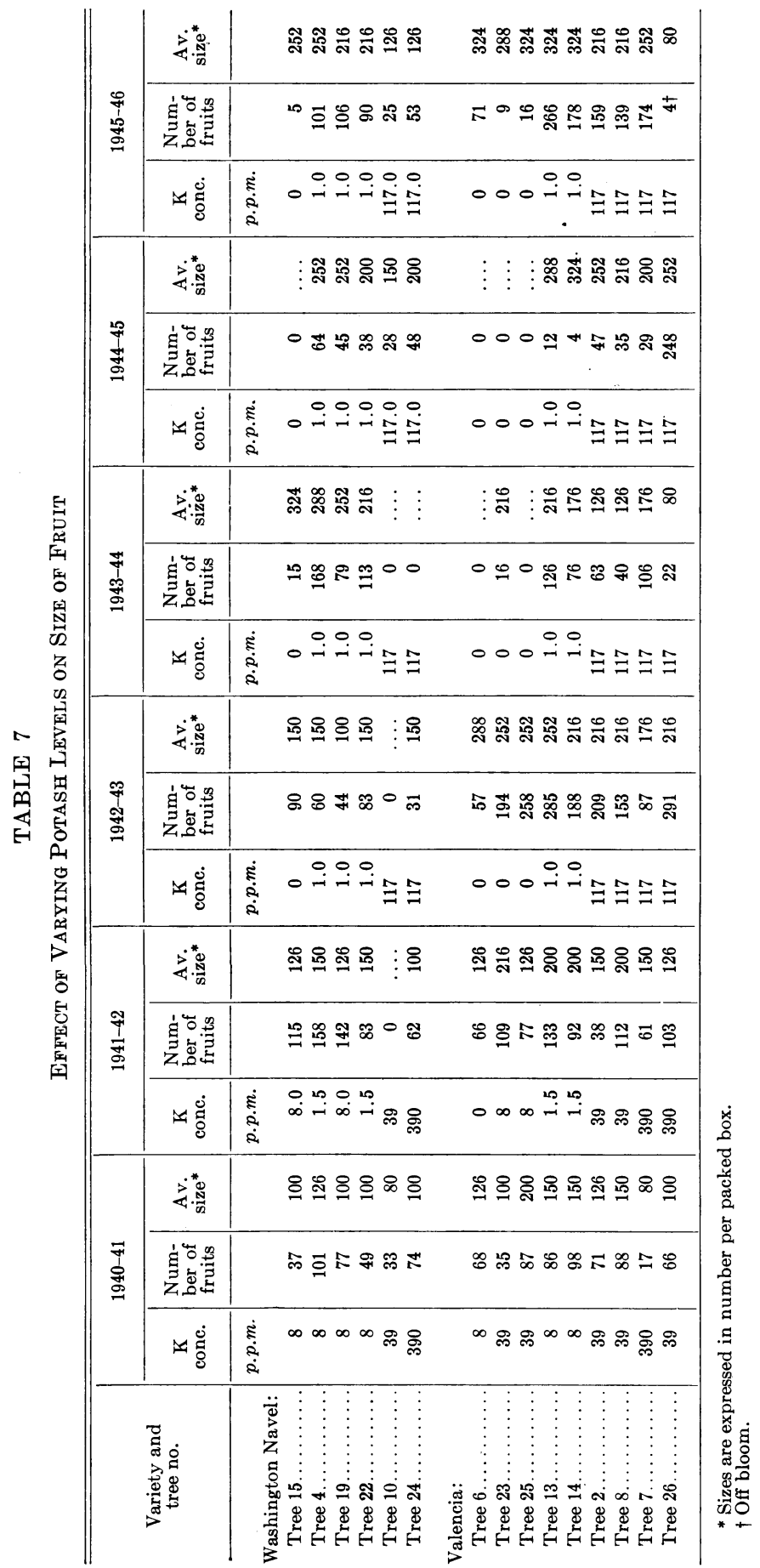


in the roots of the potash-deficient trees than in the tree receiving ample potassium. Exceptions to this, however, were the presence of tin, cobalt, and cadmium in the roots of the potassium-deficient tree. No trace of these was found in the roots of tree 26 , which received ample potash.

\section{EFFECTS OF VARYING POTASH LEVELS ON FRUIT QUALITY}

Size and Yield. The most striking and consistent effect of potassium on fruit quality was in the matter of sizes. This is shown by the data of table 7 and the color pictures in plate 6 . Even with trees $4,19,22,13$, and 14, in which only the earliest and faintest symptoms of potassium deficiency developed, there was a definite reduction of fruit size. This is a significant finding, for it indicates that although potassium may be sufficient for practically normal

TABLE 8

Number of Fruits Picked and Average Weight per Fruit in Relation to Potash Level

\begin{tabular}{|c|c|c|c|c|c|c|c|c|c|}
\hline \multirow{2}{*}{ Potash } & \multirow{2}{*}{$\begin{array}{l}\text { Number } \\
\text { of trees }\end{array}$} & \multicolumn{2}{|c|}{$1943-44$} & \multicolumn{2}{|c|}{$1944-45$} & \multicolumn{2}{|c|}{$1945-46$} & \multicolumn{2}{|c|}{$1943-46$} \\
\hline & & $\begin{array}{c}\text { Number } \\
\text { picked }\end{array}$ & $\begin{array}{l}\text { Av. wt. } \\
\text { per fruit }\end{array}$ & $\begin{array}{c}\text { Number } \\
\text { picked }\end{array}$ & $\begin{array}{l}\text { Av. wt. } \\
\text { per fruit }\end{array}$ & $\begin{array}{c}\text { Number } \\
\text { picked }\end{array}$ & $\begin{array}{l}\text { Av. wt. } \\
\text { per fruit }\end{array}$ & $\begin{array}{c}\text { Number } \\
\text { picked }\end{array}$ & $\begin{array}{l}\text { Av. wt. } \\
\text { per fruit }\end{array}$ \\
\hline Extreme deficiency...... & 4 & 31 & $\begin{array}{c}\text { grams } \\
113\end{array}$ & 0 & $\begin{array}{c}\text { grams } \\
0\end{array}$ & 101 & $\begin{array}{c}\text { grams } \\
108\end{array}$ & 132 & $\begin{array}{c}\text { grams } \\
109\end{array}$ \\
\hline Slight deficiency ........ & 5 & 562 & 137 & 163 & 136 & 741 & 119 & 1466 & 128 \\
\hline Ample......... & 5 & 231 & 263 & 407 & 144 & 525 & 150 & 1163 & 170 \\
\hline
\end{tabular}

fruit setting (see tables 7 and 8 ) and for healthy tree appearance, fruit size is definitely reduced. It appears worth while to record the data on the number of fruits picked, and the average weight per fruit for the trees of the three groups (extreme potash deficiency, slight deficiency, and ample potash). These data are presented in table 8 . There is no evidence that the set of fruit was reduced by slight potash deficiency, but the effect on size as denoted by the average weight per fruit is again manifest.

Rind Texture. Data on rind texture and stem-end coarseness for the last three years of the experiment are presented in table 9 . As indicated by the fruit pictures in plates 4 and 6 , and the data of table 9 , the fruit from the deficient and slightly deficient trees was smooth in texture with no tendency for stem-end coarseness. It was noted that, in some years, some of the fruit from the acutely potassium-deficient trees tended to be a little coarser in rind texture than that from the slightly deficient trees. Moreover, there was a tendency toward some misshapenness. The important fact, from a practical point of view, however, is that the fruit from the trees slightly deficient in potash, while small in size, was of excellent texture. Equally important is the fact that the fruit from the amply supplied trees was not only of good size but of acceptable texture (see plate $6, A, a$, and $B, c)$. With potash excessive to the point of tree injury, fruit of very coarse texture was produced. It will be recalled that trees 24,7 , and 26 received 390 p.p.m. potash in the early years of the experiment. The fruit borne during those years was consistently large, coarse, with thick rinds, coarse stem ends, and pulpy flesh. It was low in juice, and the juice was of poor quality. Even in 1943-44, tree 26 which, during 1941-42, received 390 p.p.m. potash and which, in April, 1942, was reduced 
to 117 p.p.m. potash, showed some carry-over effect, for all of the fruit was coarse-textured and the stem ends were rough (see table 8 and plate $6, A, d$ ).

Under the conditions of this experiment, there is unmistakable evidence that low potash makes for small sizes but otherwise smooth, good-quality fruit; ample or somewhat excessive potash makes for larger sizes but still fruit of acceptable quality; while a great excess of potash makes for very coarse fruit.

Puffiness and Hollow Centers. Data regarding puffiness and hollow centers are presented in table 10 . In evaluating these data, it should be emphasized

TABLE 9

Effects of Varying Potash Levels on Rind Texture and Stem-End Coarseness

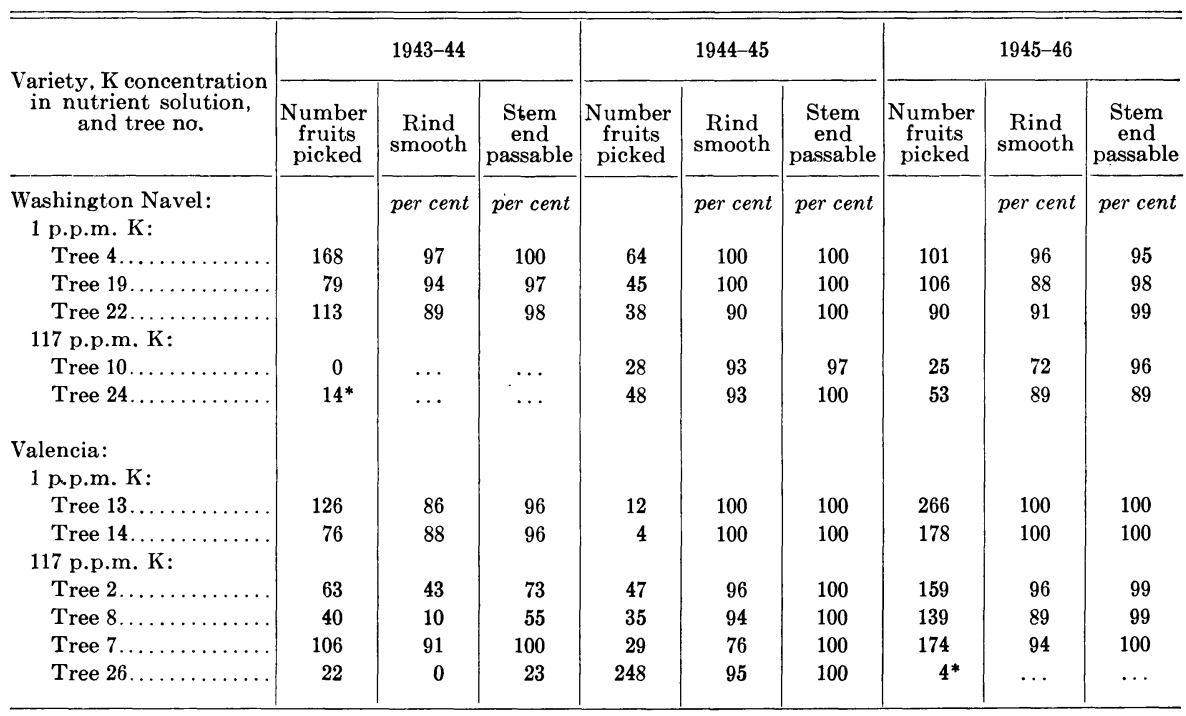

* Off bloom.

that the fruit was severely graded with respect to both of these characteristics. Any fruit which, at cutting, showed the slightest indication of puffiness (a tendency in this direction can usually be seen by close scrutiny of the albedo), or the slightest center separation, was classed either as puffy, or as having nonsolid centers. Because of this severe grading, the data of the table give the impression that the fruit produced was of poorer quality than was actually so. Such fruit as was produced on the extremely deficient trees-15, 6, 23, and 25-was very firm and showed almost no puffiness. In fact, some of the fruit was so firm it gave the impression of being hard. In most years, also, the fruit from the slightly potash-deficient trees was on the firm side with very little or no real puffiness in evidence. The fruit from the amply supplied trees was also on the firm side, showing no clear evidence that, at this potash level, puffiness is produced. Even the fruit from the excessive-potash trees showed, in general, no clear-cut tendency toward puffiness (data on these fruits not shown in table 10). Therefore, it would appear that puffiness of fruit, if related at all to nutrition, is caused by some factor other than potash supply. 
A tendency toward hollow centers was more pronounced in fruit from trees receiving excessive potash (data not shown in table 10) than from those receiving less potash. But there was no clear difference between fruit from amply supplied trees and that from trees slightly or acutely deficient.

Juice Characteristics. Table 11 shows data on soluble solids (Brix), citric acid, and vitamin C. In total soluble solids, there is no clear-cut indication of a difference. In citric acid, although the difference is not great, the high-potash

TABLE 10

Effect of Varying Potash Levels on Puffiness and Hollow Centers

\begin{tabular}{|c|c|c|c|c|c|c|c|c|c|}
\hline \multirow{2}{*}{$\begin{array}{l}\text { Variety, } \mathrm{K} \text { concentration } \\
\text { in nutrient solution, } \\
\text { and tree no. }\end{array}$} & \multicolumn{3}{|c|}{$1943-44$} & \multicolumn{3}{|c|}{$1944-45$} & \multicolumn{3}{|c|}{$1945-46$} \\
\hline & $\begin{array}{c}\text { Number } \\
\text { of fruits } \\
\text { picked }\end{array}$ & $\begin{array}{l}\text { Non- } \\
\text { puffy }\end{array}$ & $\begin{array}{c}\text { Solid } \\
\text { centers }\end{array}$ & $\begin{array}{l}\text { Number } \\
\text { of fruits } \\
\text { picked }\end{array}$ & $\begin{array}{l}\text { Non- } \\
\text { puffy }\end{array}$ & $\begin{array}{c}\text { Solid } \\
\text { centers }\end{array}$ & $\begin{array}{c}\text { Number } \\
\text { of fruits } \\
\text { picked }\end{array}$ & $\begin{array}{l}\text { Non- } \\
\text { puffy }\end{array}$ & $\begin{array}{l}\text { Solid } \\
\text { centers }\end{array}$ \\
\hline $\begin{array}{l}\text { Washington Navel: } \\
\text { 0 p.p.m. K: }\end{array}$ & & per cent & per cent & & per cent & per cent & & per cent & per cent \\
\hline Tree $15 \ldots \ldots \ldots$ & 15 & 91 & 18 & 0 & $\cdots$ & $\cdots$ & 5 & 100 & 100 \\
\hline $\begin{array}{c}1 \text { p.p.m. K: } \\
\text { Tree } 4 \ldots\end{array}$ & 168 & 97 & 50 & & 85 & 69 & & 94 & \\
\hline Tree $19 \ldots .$. & $\begin{array}{r}79 \\
79\end{array}$ & 79 & 62 & $\begin{array}{l}04 \\
45\end{array}$ & $\begin{array}{l}80 \\
85\end{array}$ & 62 & 106 & $\begin{array}{l}94 \\
38\end{array}$ & $\begin{array}{l}10 \\
32\end{array}$ \\
\hline Tree $22 \ldots$. & 113 & 89 & 47 & 38 & 72 & 59 & 90 & 65 & 33 \\
\hline 117 p.p.m. K: & & & & & & & & & \\
\hline Tree $10 .$. & 0 & $\ldots$ & $\ldots$ & 28 & 67 & 48 & 25 & 100 & 43 \\
\hline Tree 24 & $14^{*}$ & $\ldots$ & $\ldots$ & 48 & 76 & 40 & 53 & 89 & 36 \\
\hline Valencia: & & & & & & & & & \\
\hline $\begin{array}{l}0 \text { p.p.m. } \mathrm{K}: \\
\text { Tree } 6 \ldots \ldots\end{array}$ & 0 & $\ldots$ & $\ldots$ & 0 & ... & $\ldots$ & 71 & 98 & 69 \\
\hline Tree 23 & 16 & 92 & 50 & 0 & $\ldots$ & $\ldots$ & 9 & 89 & 44 \\
\hline Tree 25. & 0 & $\cdots$ & $\ldots$ & 0 & $\ldots$ & $\ldots$ & 16 & 100 & 63 \\
\hline 1 p.p.m. K: & & & & & & & & & \\
\hline Tree $13 \ldots$ & 126 & 95 & 22 & 12 & 92 & 50 & 266 & 89 & 49 \\
\hline Tree $14 \ldots$ & 76 & 79 & 27 & 4 & 100 & 50 & 178 & 88 & 62 \\
\hline 117 p.p.m. K: & & & & & & & & & \\
\hline Tree $2 \ldots \ldots$ & 63 & 96 & 8 & 47 & 98 & 37 & 159 & 92 & 36 \\
\hline Tree $8 \ldots \ldots$ & 40 & 97 & 22 & 35 & 80 & 49 & 139 & 96 & 55 \\
\hline Tree 7.. & 106 & 98 & 39 & 29 & 97 & 24 & 174 & 89 & 64 \\
\hline Tree 26 . & 22 & 6 & 0 & 248 & 72 & 31 & $4^{*}$ & $\ldots$ & $\ldots$ \\
\hline
\end{tabular}

* Off bloom.

fruit is consistently higher than the low-potash fruit. This is in accord with data reported by many others (see "Review of Literature," pages 620, 621). The vitamin-C content in the low-potash fruit does not differ significantly from that in the ample-potash fruit.

\section{EFFECTS OF POTASSIUM EXCESS}

Some reference has already been made to the effects of excess potassium on fruit quality. The trees grown for two years in solutions containing 390 p.p.m. potassium were injured. As the fruit of these trees began to size up in the winter of $1940-41,5$ to 6 months after transfer of the trees to the highpotassium cultures, it was noted that the rinds on many were extremely coarse. The fruits were large and many were misshapen. None of the fruit in the lower-potassium cultures showed these effects. This same condition developed the following season. 


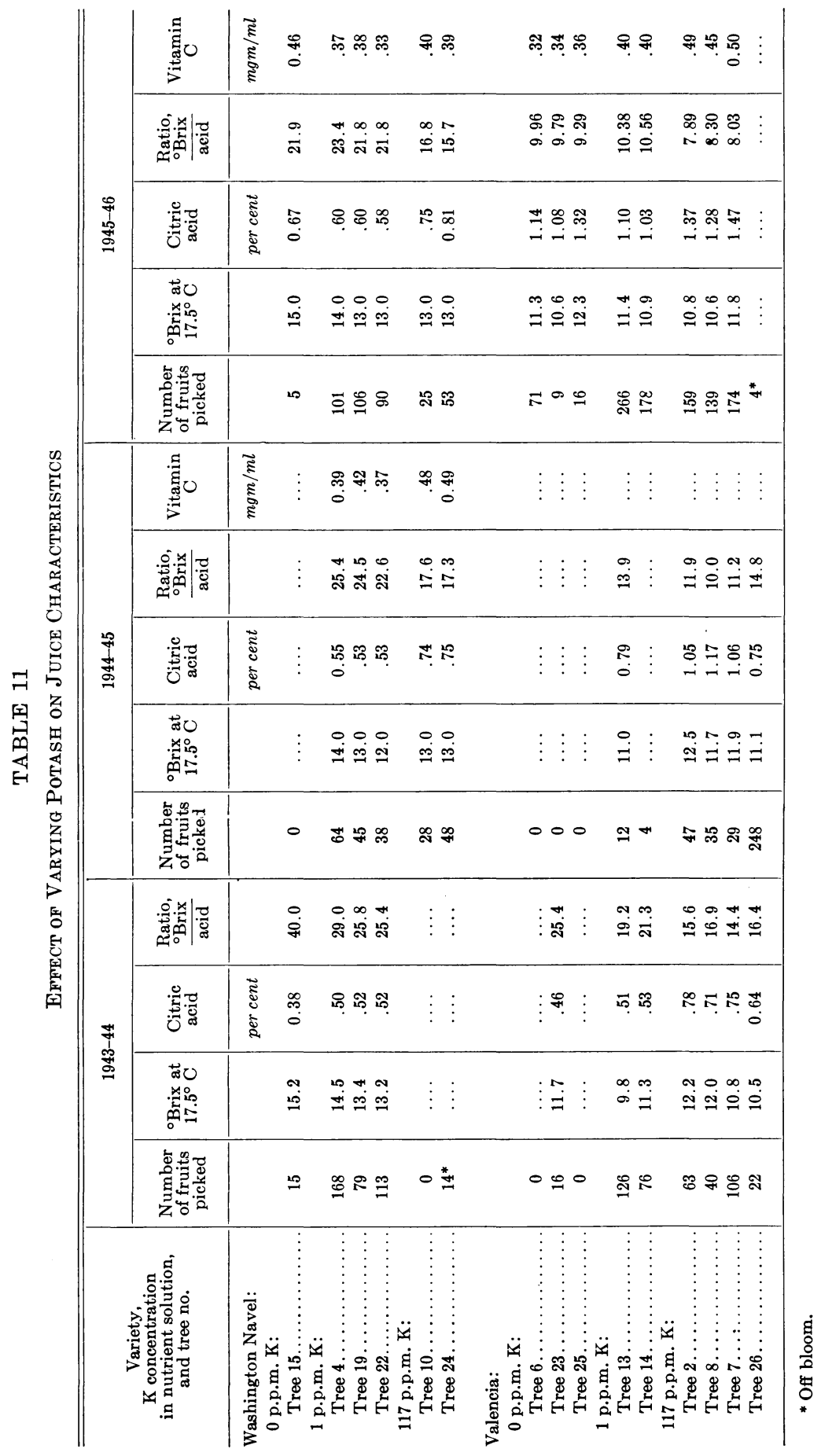


In the spring of 1941, the trees receiving high potassium began to lose more leaves than the other trees and to show less new growth. No leaf patterns, except transient manganese deficiency, and no special twig or trunk symptoms appeared. But as noted earlier and reported in a previous publication (Chapman and Brown, 1942a), a number of these high-potassium trees developed brown-rot gummosis. The leaf content of potassium ranged from 2.15 to 3.63 per cent.

With the trees which were not discarded because of gummosis, the subsequent reduction of potassium to 117 p.p.m. resulted in their recovery. The leaf content of potash gradually dropped, the trees put out new, vigorous growth, and the fruit produced was of good quality, although, as noted, a carry-over effect on the fruit of tree 26 was evident in 1943. (See plate 6.)

\section{DISCUSSION}

The effects of potassium deficiency on fruit, growth, and foliage characteristics, as produced under the conditions of this experiment, are in harmony, for the most part, with those reported by other authors for citrus.

No definite or specific leaf patterns, such as characterize zinc, manganese, and iron deficiencies, distinguish this disorder. Leaf scorch of the type described for many other plants (Eckstein, Bruno, and Turrentine, 1937; Hambidge, 1941) is conspicuously absent on citrus. Leaf curling, puckering, and malformation of many variations mark the acute stages. This is accompanied by more or less fading of the chlorophyll ; some of the leaves may show a yellow spotting. The brown pustular spots on leaves, described by a number of investigators (Bryan, 1935; Haas, 1936 ; Hambidge, 1941), were not seen either on the bearing trees or on the potash-deficient orange and lemon seedlings grown in the greenhouse. In the spring following bloom, some of the old senescent leaves showed a fine peppering of brownish spots on parts of the leaf, but this same type of spot was seen on the leaves of the amply supplied trees, although not, perhaps, in such great abundance. It is probable that the production of brown spots is a secondary condition which develops only under certain special climatic or nutritional conditions. The senior author has seen brown peppery spots on citrus leaves under so many conditions in the field, where no other symptoms of potassium deficiency occurred and where leaf analysis gave no indication of potassium lack, that he cannot accept peppery spots as a reliable criterion of potassium deficiency.

An interesting feature of potash lack in citrus is the more or less regular occurrence of iron chlorosis. Interference with iron metabolism, under conditions of potassium deficiency, has been noted on other plants (Hambidge, 1941). In both the present and a former experiment, excessive accumulation of boron in the leaves and the occurrence of typical boron-excess symptoms have been noted, especially where the boron content of the nutrient medium was somewhat on the high side.

While no.one symptom can be thought of as being peculiarly specific for potassium deficiency, the combination of symptoms-namely, leaf curling, fading of chlorophyll, thickened leathery leaves, excessive leaf drop following spring-cycle growth, dieback of shoots, coupled with a low-potassium and high-calcium and -magnesium content of the leaf-would enable a positive 
diagnosis where the condition is fairly acute to subacute. On the other hand, the very earliest stages of deficiency are marked by an almost complete lack of specific foliar or growth symptoms. The most suggestive symptoms would be a low-potassium level in the leaves, small fruit sizes, and a tendency toward above-average leaf drop following spring bloom. While, under the conditions of this experiment, a leaf content of around 0.3 per cent potassium was associated with this condition, it will require much further study to determine whether, under all conditions, this particular level of potassium reliably represents the earliest stage of potassium deficiency. It appears more likely that the ratio of potassium to some one or more constituents of the leaf will prove a more accurate basis. This question will be discussed in greater detail in a paper to follow, which will describe the authors' leaf-analysis research.

TABLE 12

Production Record of Tree 26

\begin{tabular}{|c|c|c|c|c|}
\hline Crop year & $\begin{array}{l}\text { Potassium in } \\
\text { nutrient } \\
\text { solution }\end{array}$ & $\begin{array}{c}\text { Potassium } \\
\text { in } \\
\text { leaves }\end{array}$ & $\begin{array}{l}\text { Number } \\
\text { of fruits } \\
\text { picked }\end{array}$ & $\begin{array}{c}\text { Average } \\
\text { sizes }\end{array}$ \\
\hline $1939-40$. & $\begin{array}{c}\text { p.p.m. } \\
39.0\end{array}$ & $\begin{array}{c}\text { per cent } \\
\ldots\end{array}$ & 54 & 176 \\
\hline $1940-41 \ldots \ldots \ldots$ & 39.0 & 0.86 & 66 & 100 \\
\hline $1941-42 \ldots \ldots \ldots \ldots \ldots$ & 390.0 & 2.63 & 103 & 126 \\
\hline $1942-43 . \ldots \ldots \ldots \ldots \ldots \ldots \ldots \ldots \ldots \ldots \ldots \ldots \ldots$ & 117.0 & 3.07 & 291 & 216 \\
\hline $1943-44 \ldots \ldots \ldots \ldots \ldots \ldots \ldots \ldots \ldots \ldots \ldots \ldots \ldots$ & 117.0 & 1.94 & 22 & 80 \\
\hline 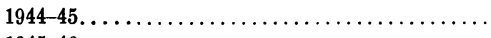 & 117.0 & 1.36 & 248 & 252 \\
\hline $1945-46 \ldots \ldots \ldots \ldots \ldots \ldots \ldots \ldots \ldots \ldots \ldots \ldots \ldots$ & 117.0 & 1.39 & $4^{*}$ & 80 \\
\hline
\end{tabular}

* Off bloom.

With regard to fruit quality, the most significant finding is that the earliest stage of potassium deficiency results in smaller sizes. The indications are that this effect is not necessarily accompanied by a decrease in blossom or in fruit setting. The data obtained on size are in harmony with those published by others. In an experiment on Norfolk sand in Florida, Bahrt and Roy (1940), mentioned earlier, found that lack of potassium decreased both yield and size of oranges. Neetles and Forsee (1941), in a field experiment on peat soils in Florida, report that larger sizes were produced where potash was added. Benton and Stokes (1931), in Australia, report that smaller sizes resulted in their no-potash plots. These results from different parts of the world indicate beyond doubt that potassium deficiency, even in its earliest stage, results in reduced fruit sizes.

It is not to be inferred from this paper that ample or excessive potash will assure large sizes. Some evidence on this point was obtained in this experiment. Tree 26 (Valencia) which, for one year, was given 390 p.p.m. potassium, later reduced to 117 p.p.m., showed pronounced alternate-bearing tendencies during the last four years of the experiment. For convenience, the record of nutrient supply and of leaf content of potassium, total fruit picked at harvest, and average size for tree 26 are reproduced in table 12. The relation between the number of fruits produced and size is strikingly illustrated in the behavior of this tree. Despite an ample supply of potassium in the nutrient medium and in the leaves during the years $1942-43$ and $1944-45$, the sizes, 
especially in 1944-45, tended toward smallness. The authors are convinced that while nutrition, particularly the potassium supply, affects size, factors such as climate, alternate bearing, and water supply are also involved.

One other point should be mentioned: There is no support in the authors' work or in experiments in any other part of the world for the idea that increased potash makes for smoother fruit of greater juice content and higher total solids. All of the evidence indicates that just the opposite occurs-that is, increased potash tends to produce somewhat coarser, although not necessarily unacceptable fruit. Such fruit colors up later than that from low-potash trees, and the high-potash fruit shows increased acidity.

\section{SUMMARY}

Budded four-year-old Washington Navel and Valencia orange trees were grown for six years in out-of-door controlled-nutrient cultures under variable conditions of potassium supply. For a period, some of the trees were subjected to excessive potash, and, for comparison, others were grown in solutions of adequate but not excessive supply, while still others were partially and completely deprived of potassium. Systematic records of tree appearance, growth, fruit production, fruit quality, and inorganic composition were made.

Trees suffering from acute potash deficiency showed pronounced twisting, curling, and puckering of leaves, and a considerable but more or less patternless fading of chlorophyll. No leaf scorch was seen. Branch and shoot dieback occurred,' new growth was weak, and leaves were undersized. Blossoms were sparse and few fruits were produced. The fibrous roots of potash-deficient trees, while of good color, were rather stubby and somewhat enlarged. On potash-deficient trees, the fruit which matured, although small, was firm and of good quality. Where potash was only slightly deficient, the chief effect on fruit was a reduction in size. Otherwise it was smooth, thin-skinned, juicy, of good acid and total-solids content; and vitamin $\mathrm{C}$ was normal. The taste and eating quality were not impaired. In comparison with fruit from trees receiving adequate potash, acid was significantly less, although the difference was not great. The fruit from potash-deficient trees colored up earlier than fruit from trees not deficient.

Trees only slightly deficient in potash were healthy in appearance, showing no clear-cut, visible symptoms by which this stage of deficiency could be diagnosed. However, the leaf content of potassium was low. No significant impairment of fruit set was noted.

Excess potash, to the point of tree injury, on the other hand, made for large, coarse fruit with thick skin, coarse flesh, and poor eating quality. Trees so affected became defoliated and dwarfed, but no characteristic leaf pattern or burn was seen. At intermediate potash levels, fruit was of good size and quality. Apparently the potassium level in the tree may vary through a fairly wide range without affecting growth and appearance materially.

Orange trees can apparently secure ample potash from a very low maintained supply. At concentrations ranging from 2 to 3 p.p.m. potassium, under the conditions of this experiment, no signs of potash deficiency developed. At concentrations of 390 p.p.m. potassium (ranging from 350 to 400 p.p.m.), the trees were injured. At 117 p.p.m., no ill effects were seen. 
Leaves of comparable age were found to reflect the potassium status of the culture medium very well. The range between acute potash deficiency and excess was from about 0.10 per cent to 3.8 per cent potassium on a dry-matter basis.

\section{ACKNOW'LEDGMENTS}

Our soil and plant nutritional researches on potash, of which the work reported in this paper is a part, have been aided by a yearly grant from the American Potash Institute. The authors wish to express their sincere thanks and appreciation for this support.

The authors are indebted to Dr. A. P. Vanselow for the spectrographic analyses made of culture solutions and leaf tissue reported in this paper and also for numerous spectrographic analyses of distilled and tap water, and of the chemicals used in this work; and to Dr. L. J. Klotz for the bioassay of the roots infected with Phytophthora parasitica. They are also indebted to Mr. George F. Liebig, Jr., for determinations of vitamin C on the fruit juice, and for miscellaneous assistance of other kinds rendered during the course of this experiment. 


\section{LITERATURE. CITED}

ALLWRIGHT, W. J.

1938. Final report on the fertiliser trials at Rustenburg, western Transvaal. Citrus Grower 52:5-19.

ANDERSSEN, F. G.

1937. Citrus manuring-its effect on cropping and on the composition and keeping quality of oranges. Jour. Pomol. and Hort. Sci. 15:117-59.

Bahrt, George M., and Wallace R. Rox.

1940. Progress report of the effect of no potassium and various sources and amounts of potassium on citrus. Florida State Hort. Soc. Proc. 53:26-34.

Benton, R. J., and W. B. Stokes.

1931. The value of potash as a fertiliser for citrus trees. Agr. Gaz. New South Wales $42: 889-92$.

BRYAN, O. C.

1935. Potash deficiency in grapefruit. Florida Grower 43:14-16.

Camp, A. F., L. W. Gaddum, and A. L. Stahl.

1933. Cold storage studies on eitrus fruits. Florida Agr. Exp. Sta. Ann. Rept. 1933:104-09.

Chapman, H. D., George F. Liebig, JR., and A. P. Vanselow.

1939. Some nutritional relationships as revealed by a study of mineral deficiency and excess symptoms on citrus. Soil Sci. Soc. Amer. 4:196-200.

Chapman, H. D., and S. M. Brown.

1942a. Some fungal infections of eitrus in relation to nutrition. Soil Sci. 54:303-12.

1942b. Potash in relation to citrus nutrition. Soil Sci. 55:87-100.

Collison, S. E.

1913. Influence of soil and fertilizer on citrus fruits. Florida State Hort. Soc. Proc. $26: 168-72$.

Eckstein, Oskar, Albert Bruno, and J. W. Turrentine.

1937. Potash deficiency symptoms. Verlagsgesellschaft für Ackerbau. M.B.H. Berlin, S.W. 11.

HAAS, A. R. C.

1932. Some nutritional aspects in mottle leaf and other physiological diseases of citrus. Hilgardia 6(15) : 483-559.

1936. The growth of eitrus in relation to potassium. California Citrog. 22:6, 17, 54, 62 .

Hambidge, Gove (ed.).

1941. Hunger signs in crops. American Society of Agronomy and National Fertilizer Association, Washington, D.C.

MORRIS, A. A.

1937. The effect of differential fertilizer treatments on the yield and quality of fruit from mature bearing Valencia late trees on Mazoe citrus estate, southern Rhodesia. Brit. So. Afr. Co. Pub. 6 (Mazoe Citrus Exp. Sta. Rpt. 1936) :107-53.

NeEtles, J. R., and W. L. Forsee, JR.

1941. Fertilizer experiments in an orange grove in the eastern Everglades. Citrus Indus. 22:6-7.

OPPENHEIMER, H. R., and K. MENDEL.

1938. Problems of citrus nutrition II. Studies on the potash requirements of sweet lime. Hadar 11:177-81, 244-49.

Parker, E. R., and L. D. Batchelor.

1942. Effect of fertilizers on orange yields. California Agr. Exp. Sta. Bul. 673:1-39.

Provan, J. L.

1938. Fertiliser experiment. Phosphoric acid and low acidity. Citrus News 14:114-16. 
REED, H. S., and A. R. C. HAAS.

1923. Studies on the effects of sodium, potassium and calcium on young orange trees. California Agr. Exp. Sta. Tech. Paper 11:1-33. (Out of print.)

RoY, WALlace R.

1945. Effect of potassium deficiency and of potassium derived from different sources on the composition of the juice of Valencia oranges. Jour. Agr. Res. 70:143-69.

VAN Der Plank, J. E., and F. A. S. Turner.

1936. Are our sour oranges due to lack of phosphorus? Farming in South Africa 11:59-60.

WeBber, HeRBERT JoHN.

1895. Fertilization of the soil as affecting the orange in health and disease, U.S. Dept. Agr. Yearbook 1894:193-202.

Young, H. D.

1917. Effect of fertilizers on the composition and quality of oranges. Jour. Agr. Res. $8: 127-38$. 



\section{PLATES}





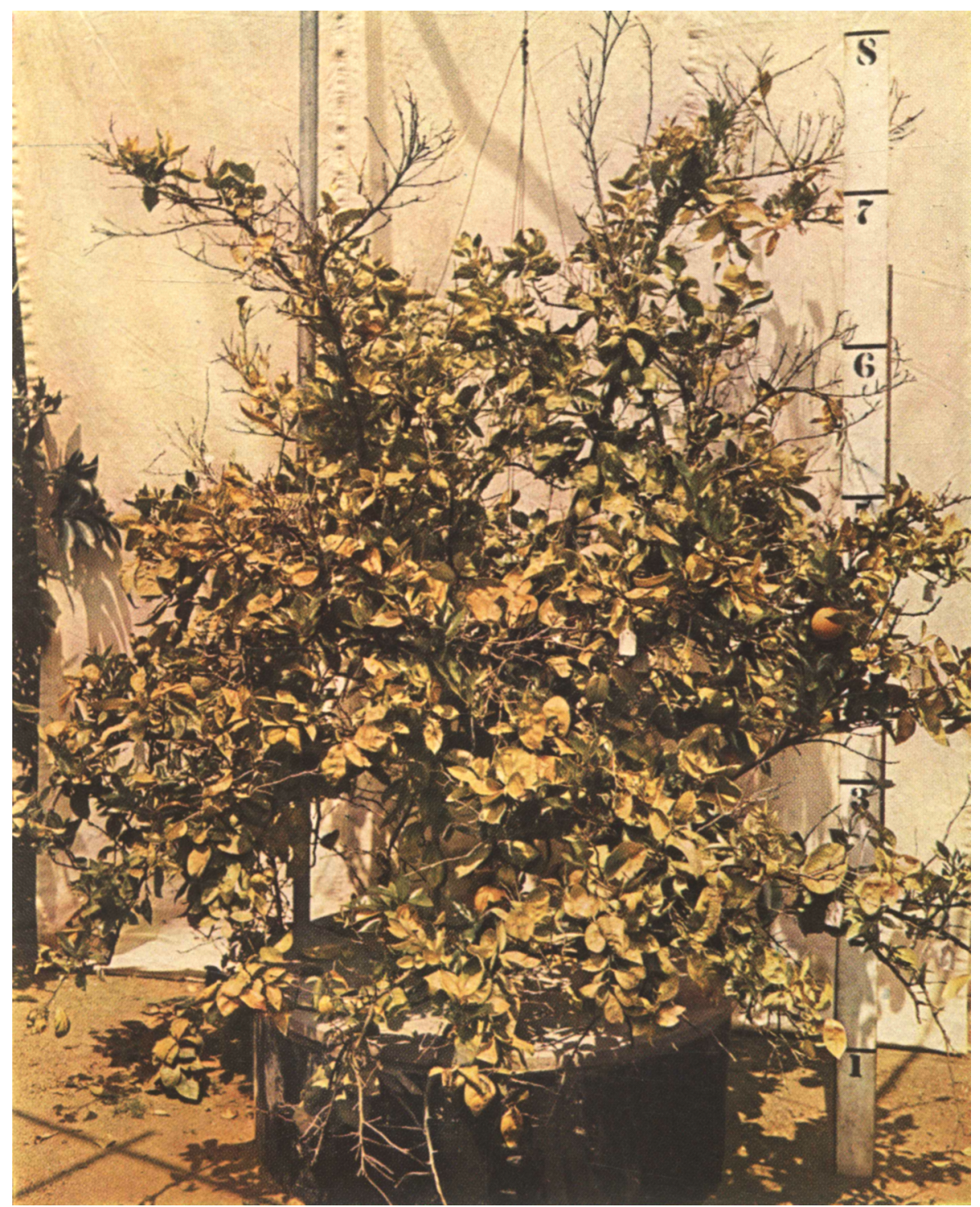

Plate 1.-Valencia orange tree showing effects of acute potassium deficiency. (Tree 26, photographed in April, 1946.) 


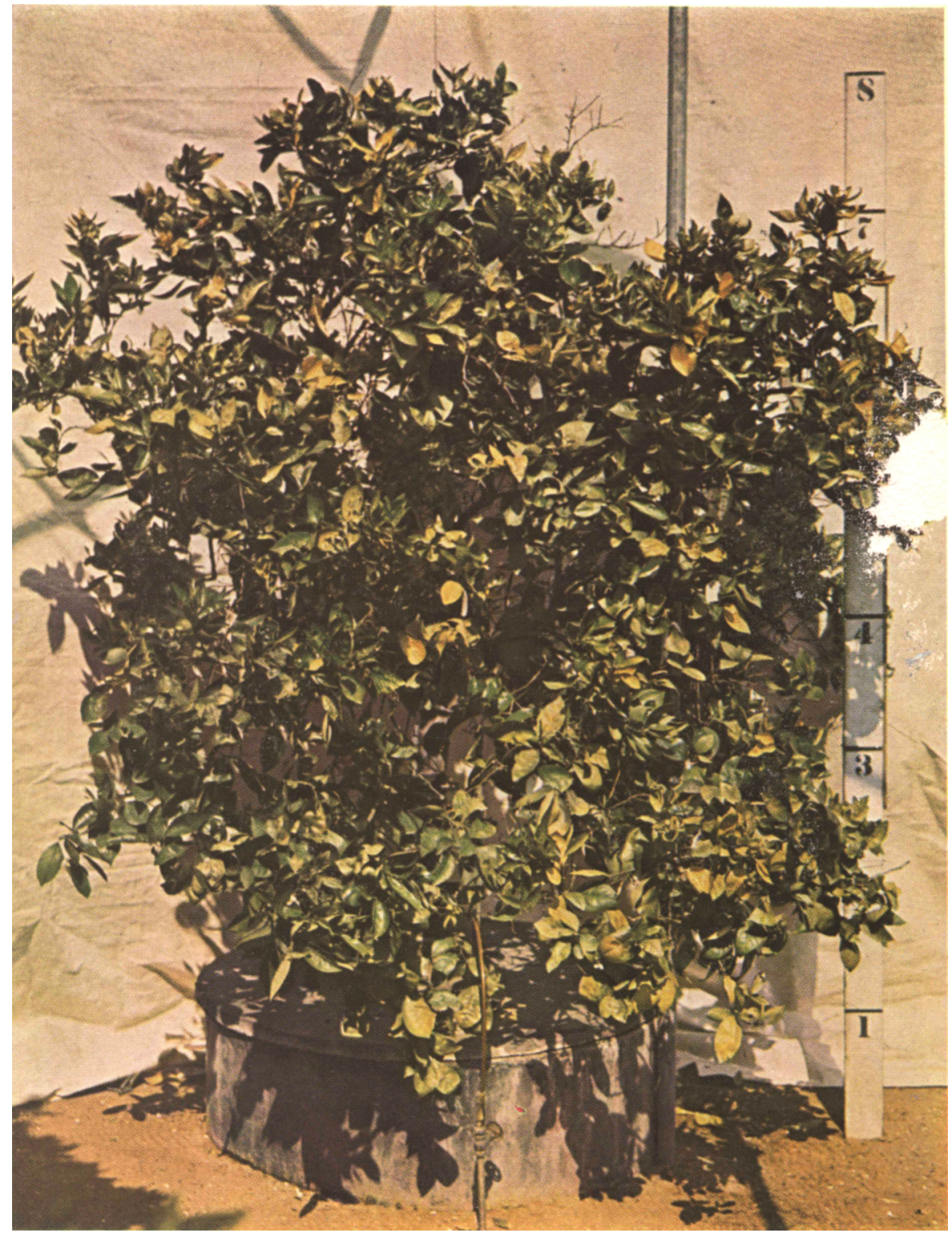

Plate 2.- Valencia orange tree showing effects of moderate potassium deficiency. (Tree 6, photographed in April, 1946.) 


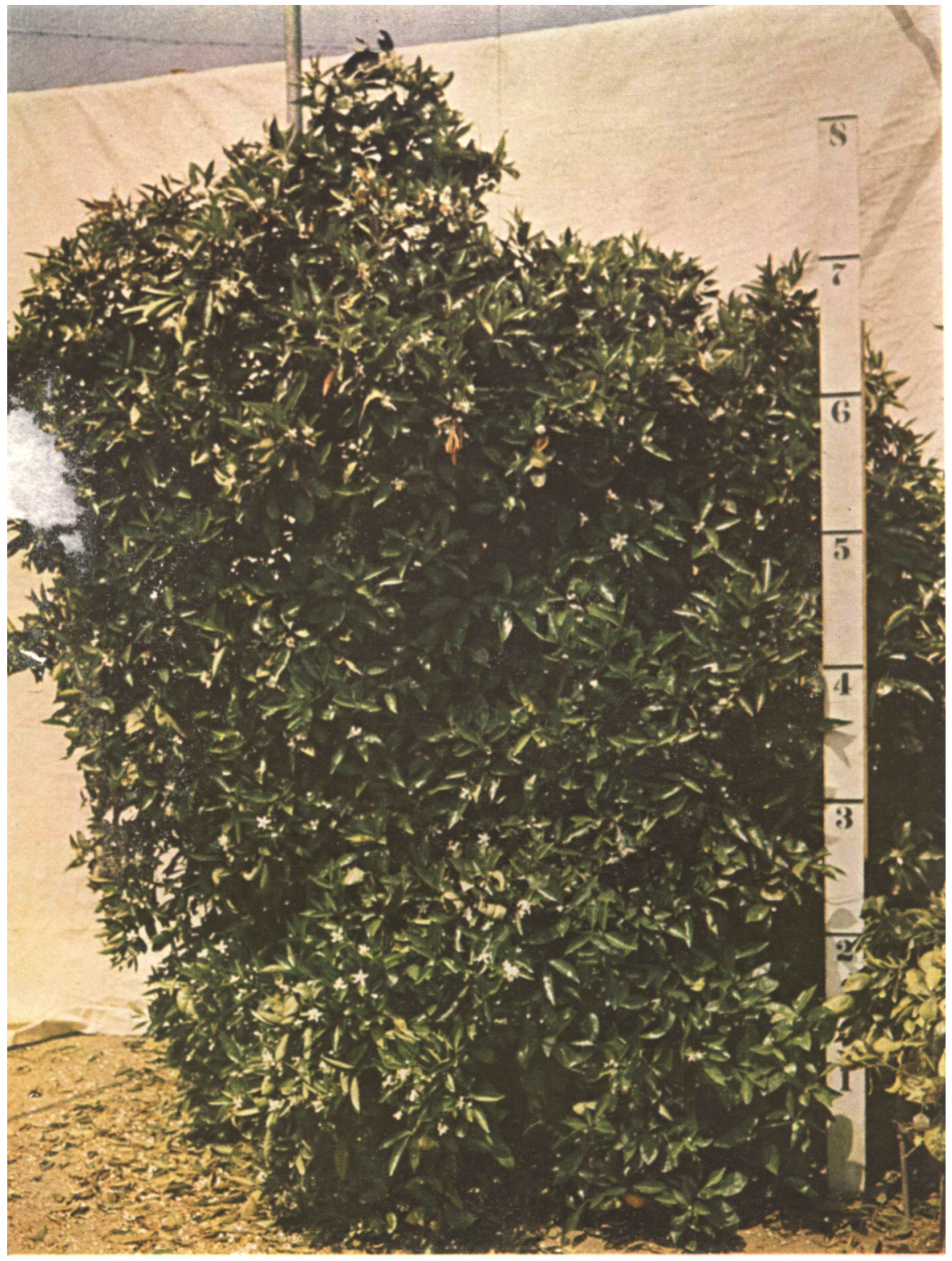

Plate 3.-Washington Navel orange tree showing comparatively normal appearance at earliest stage of potassium deficiency. (Tree 4, photographeã in April, 1946.) 
A $\quad$ B $\quad$ C



Plate 4.- Various effects of potassium deficiency on foliage and fruit: $A$, appearance of fruit and foliage in November on tree receiving ample potassium; $B$, appearance of fruit and leaves from tree slightly deficient in potash (photograph taken at same time as $A$ ) ; $C$, appearance of fruit and leaves from tree acutely deficient in potash $; D$, yellow color and abnormal drop of older leaves on potassium-deficient tree following spring cycle; $E$ and $F$, yellow color and curling of leaves on tree acutely deficient in potassium. 


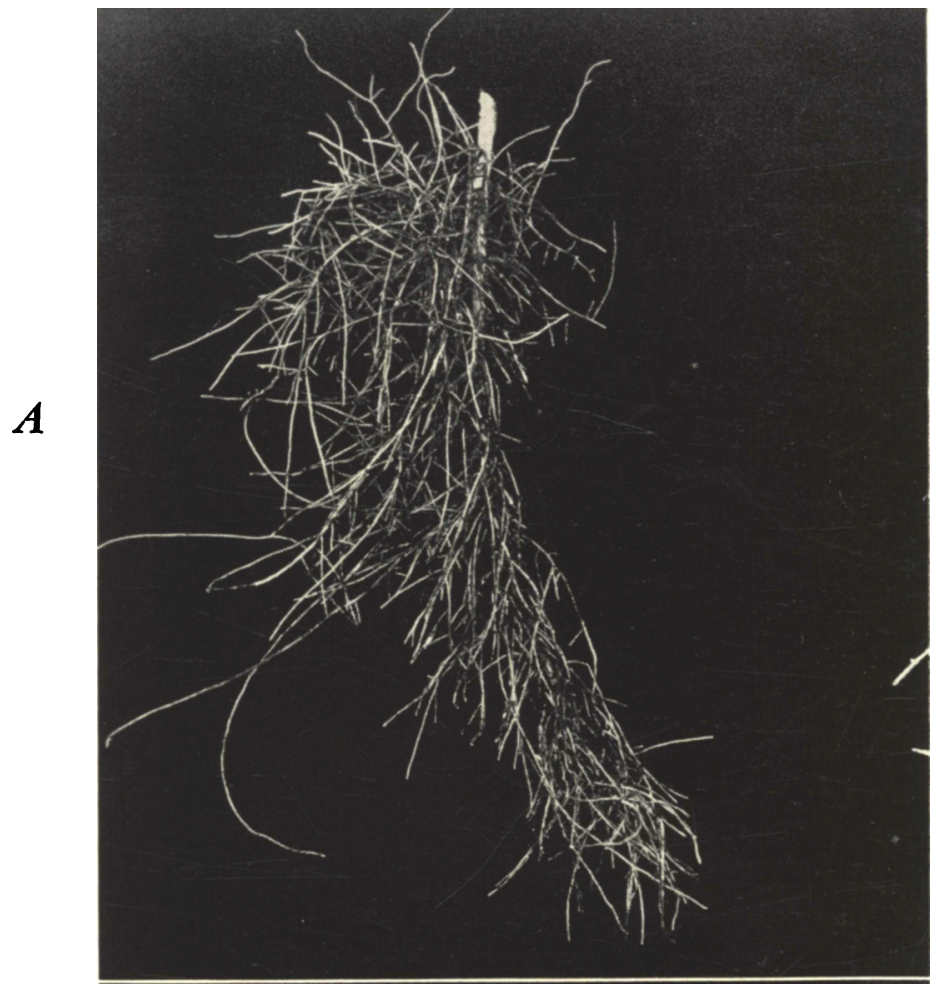

Plate 5.- $\boldsymbol{A}$, character of roots from tree receiving ample potash; $B$, roots

from tree deficient in potash. Note short laterals and thickening.

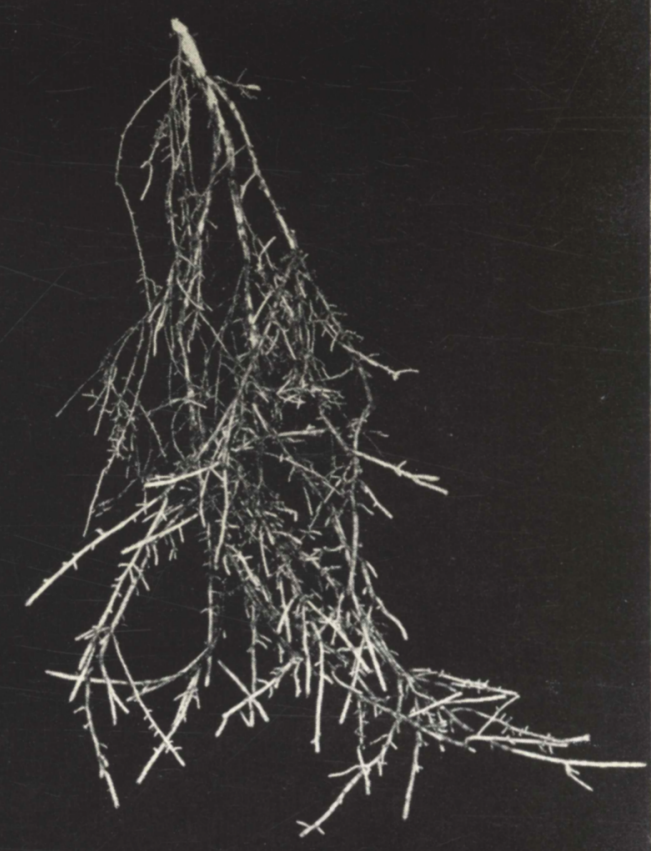




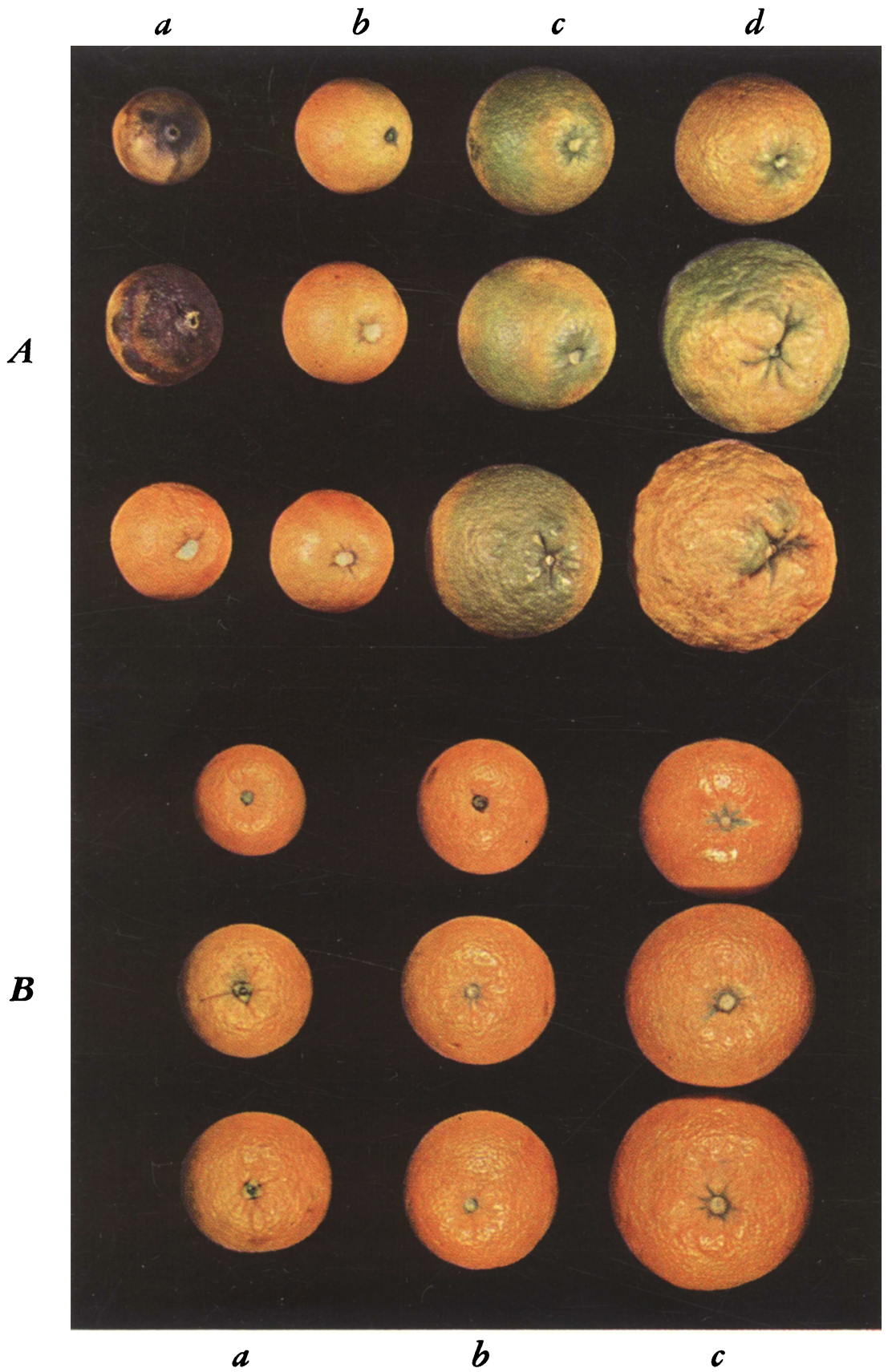

Plate 6.-Effects of varying potash supply on size and texture of oranges: $A$, Valencia oranges picked in October, 1943: a, Fruit picked in October from trees suffering from acute potassium deficiency. The stems died back on some of these, leading to necrosis of the stem and of the fruit. $b$, Fruit from tree only slightly deficient in potash. $c$, Fruit from tree receiving ample potash. $d$, Fruit from tree receiving excessive potash. $B$, Navel oranges picked in 1944: $a$, Fruit from acutely potash-deficient tree. $b$, Fruit from tree slightly deficient in potash. $c$, Fruit from tree receiving ample potash. 


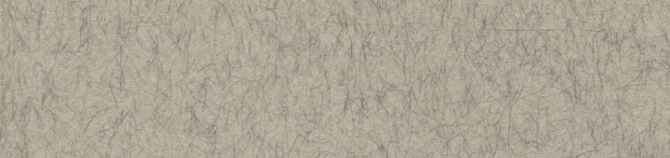

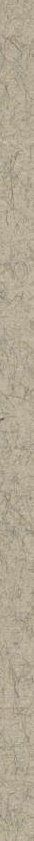

